Case x.-C. W. aged 36. Admitted July 29th, 1890, for psoas abscess. Has had pain in the lumbar region for three years. A tender spot present at the level of the iliac crest. No prominent spinous processes. Has noticed a swelling in the thigh for the last fortnight. Present condition: Smooth and rounded swelling on the inner side of the femoral vessels.

August 7th. Aspirated, 6 ounces of pus removed, cavity injected with 1 ounce of iodoform solution.

August 21st. Aspirated, 10 ounces of pus removed, again injected with iodoform solution.

September 18th. Aspirated, $5 \frac{1}{2}$ ounces of thin watery pus of a light brown colour removed; the pus did not smell of iodoform; cavity again injected.

September 20 th. Made an out-patient, wearing a spinal support, there being no further collection of fluid in the abscess ravity.

February, 1891. The patient returned to the infirmary after five months' absence in order to inquire if he was to continue wearing the spinal support. There was no sign of recurrence of the abscess or mark to show where the puncture had been.

REMARKS. - In all cases strict antiseptic precautions are observed as to hands, instruments, and skin over the site of puncture. At first the carbolic spray was used, but of late I have ceased to employ it in any operation. If the pus be thick and incapable of evacuation by the aspirator a good sized trochar is employed. As a rule an anæsthetic is not administered, although when the ether expands some little pain is felt; this, however, rapidly passes away. It will be noted that whilst the emptying of the abscess and the injection of the cavity forms an important part of this method of treatment the disease causing the abscess is not forgotten. The patient is for some weeks kept recumbent, and is afterwards supplied with a correctly-fitting spinal support, which is worn for at least a year or until the spinal disease is well. My reason for bringing these cases forward is that I believe that this simple method of treatment is not generally known, or if known is certainly not usually followed out by the majority of surgeons ; and that now from an extended experience I can fully and confidently recommend it.

\section{A CASE OF POISONING BY "FAINTS."}

\author{
BY JAMES SWAIN, M.D., M.S.LOND., F.R.C.S.ENG.
} Senior Resident Officer Bristol Royal Infirmary.

r. H., male, aged 57 , was brought into the Bristol Royal Infirmary dead on June 25th, 1890 . At the post-mortem examination, fourteen hours after death, rigor mortis was beginning to pass off. The body was well nourished, and there were no signs of injury. Hypostasis was well marked. On opening the body, there was a strong smell resembling nitrite of amyl, but somewhat sweeter, which pervaded all the organs and fluids of the body. The lungs were congested and wdematous, but otherwise healthy. Kidneys rather dark; no diminution in size of cortex, and capsule peeled off easily. The liver was normal and weighed 60 ounces spleen slightly adherent and rather soft. The mucous membrane of the stomach was soft and thick, and the contents consisted of about 3 ounces of reddish grumous material. The red colour was shown to be due to blood, both by the guaiacum and the microscopic tests. The ventricles of the brain contained about $1 \frac{1}{1} \mathrm{oz}$. of clear fluid, having the odour above mentioned. The heart was slightly fatty, the cavities in a state of contraction, and the aortic valves and aorta were somewhat atheromatous. The contents of the stomach the fluid of the ventricles. a portion of brain matter, and about 3 ounces of urine found in the bladder were saved for examination.

At the inquest on the following day it was elicited that the deceased was a heavy drinker, and his widow stated that he was in the habit of drinking heavily of "faints," which could he obtained in large quantities from a distillery for nothing. Many of the jurymen said that they had frequently heard of "faints" being used externally for rheumatism, but never knew of its internal administration.

I requested the coroner's officer to obtain some "faints" 7 for me, and I found that it answered to the same tests as the fluids saved for examination. As I am not aware of any record of death occurring from this substance before, and as only slight reference is made to it in the ordinary textbooks of toxicology, I may be permitted to mention some of its properties.

The "faints" is the latter portions of the distillate obtained on rectifying crude spirits of wine from fermented potatoes, etc. It is rich in alcohols which are less volatile than ordinary alcohol and ether, and for practical purposes may be said to consist chiefly of fusel oil (amylic alcohol) mixed with large quantities of the secondary and primary propyl alcohols and the higher homologues of the alcohols and ethers (Rabuteau).

"Faints" has an odour of bad spirits, and owing to the presence of large quantities of amylic alcohol, it yields an odour resembling jargonelle pears, when heated with an acetate and strong sulphuric acid, due to the formation of amyl acetate.

Dr. Fürst, of Berlin, and Dr. W. B. Richardson, by experimenting, the former on rabbits, and the latter on various animals, have shown fusel oil to cause nausea, giddiness, lessened sensibility to pain, and loss of muscular power. They supposed that it acted more powerfully when breathed as a vapour than when taken internally as a liquid. It has at first a powerful intoxicating effect, followed by a period of marked depression. Its superior intoxicating effect is said to be known amongst the consumers of corn brandy in some of the northern countries of Europe, who frequently demand to be served with a "glass of good fusel."

Clinically the above case is of great interest, for in spite of the man's having the habit of taking large quantities of fusel oil (which is considered the most poisonous part of bad spirits) for the greater part of his life, his organs nowhere exhibited any greater degeneration than might be expected in a hard working man of his age, and especially should it be noted that cirrhotic changes in the liver and kidneys were entirely absent.

Finally, I would point out that the habit of drinking "faints," though perhaps not common, is practically without restriction, inasmuch as the substance can be obtained for nothing at various distilleries. This latter fact appears to deserve the attention of the "Select Committee appointed by the Chancellor of the Exchequer to consider the propriety of taking means to prevent the introduction into public use of raw and immature spirits."

\section{THE PATHOLOGY OF GANGLION:} BY WALTER G. SPENCER, M.S. Assistant Surgeon, Westminster Hospital.

WHIr.ST there can only be few chances of examining post-mon tem cases of ganglia, the opportunities which the surgical treatment by excision afford enable a conclusion to be formed of the pathology in the majority of cases, which is certainly more simple than that which has often been given by writers on surgery. I have had a good many patients under my care in whom ganglia have been caused by one of two conditions-first, a sprain or blow causing an immediate effusion of blood into the tendon sheath; the remains of the blood clot are to be found more or less organised as a solid mass within the ganglion; secondly, tenosynovitis, at first acute, later on becoming chronic; the tenosynovitis is generally caused by the overuse of some particular muscle in the work of the patient, especially when the work has only lately been taken up.

Thus, in the case of a boy, his work in the printing office obliged him constantly to twist and adduct his right hand, and to contract the flexor carpi ulnaris muscle. When first seen there was acute tenosynovitis in the tendon sheath of this muscle immediately above the wrist: later on the tenosynovitis became chronic, and a fluid swelling about $1 \frac{1}{2}$ inch long formed by distension of the sheath. Melon seed bodies could be felt in it. In a case recently operated upon the pati int had been put to work a lift by pulling on a rope so as to use excessively the extensor communis digitorum. Tena- 
synovitis was set up in the extensor sheath on the back of the wrist, and after a time a ganglion formed. Another patient, a domestic servant, put much strain on the right index finger in her occupation. An effusion occurred into the sheath of the flexor tendon on the palmar surface of the first phalanx. The effusion persisted for a year in a subacute and chronic condition. When the flexor tendons were exposed by an incision, they were found to be pushed forwards by two solid bodies about the size of peas, similar to those found in joints, lodged between the tendons and the palmar surface of the phalanx. A cure with free movement resulted from their removal. Similar ganglia have been found on the dorsal surface of the foot, the tenosynovitis being produced by the rubbing of the boot.

My observations, therefore, show that a ganglion is usually produced by a shutting off of a portion of the tendon sheath by inflammation, so that, as the diagrams indicate, the tendon forms part of the wall of the ganglion.

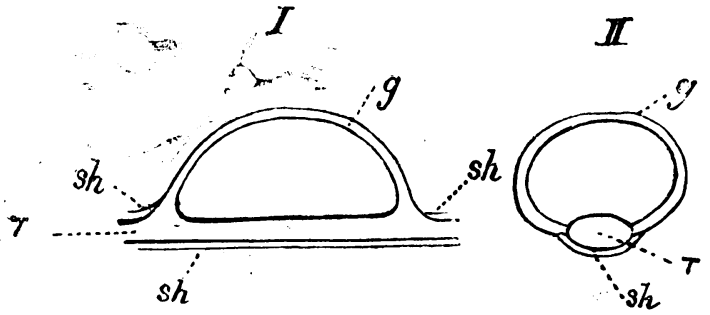

I'. Tendon. sh. Sheath of tendon, not altered. $g$. Wall of ganglion, consisting of the dilated and thickened sheath. I. Diagram of section through a ganglion.

The chief complaint of a patient suffering from a ganglion is that of diminished power in the muscle affected. This is clearly due to the firm adhesion of the tendon to the wall of the eyst, which prevents it moving freely in its sheath. In all the eases upon which I have operated the loss of power was sufficient to prevent the patient following his occupation. A common method of treatment is forcibly to rupture the cyst, and so allow the tendon to move freely in its sheath again. This can only result in cure when the amount of inflammation has beren small and is still capable of absorption. The injection of iodine, etc., inereases the amount of inflammatory tissue, and so fixes the tendon more firmly. If the sac wall be excised and passive movement begun early, the tendon regains free movement and the patient his former power. If the ganglion has become compound by extension from one of the flexor tendon sheaths above the wrist into the palm, an incision should be made at either end of the sac and the cavity washed out, after which the incision may be completely closed. The ganglion may not fill again; if it does so, a seton of several strands of silver wire may be passed through, and if careful antiseptic precautions be observed no suppuration will occur, but just sufficient inflammation will have been set up, when the wire is removed after a few days, to cause union to take place between the walls of the ganglion.

I have not had under my care a case of primary tuberculous lisease of the tendon sheath. Several children have had tubereulous abscesses in tendon sheaths of the hand or foot, but in all the cases caries of the adjacent bone was found to be the primary lesion. Such cases heal without further suppuration after scraping and application of boracic acid powder is a dressing.

WATFord (I'opulation, 17,000).-Influenza.--The general tone of Dr. Brett's rather brief report is favourable, though the death-rate of 1890 (14.5 per 1.000) showed a slight advance on that of the previous year. The proportion of deaths per 1,000 from zymotic diseases is 0.76 , a remarkably low rate Influenza was very prevalent, but not fatal, and there was no approach to any ether kind of epidemic. Some sanitary waits, which the health oflicers appears to have previously vointed out to the local board. seem to be still undealt with by that body.

\section{MEM ORA NDA:}

\section{MEDICAL, SURGICAL, OBSTETRICAL, THERA- PEUTICAL, PATHOLOGICAL, ETc.}

NOTE ON THE DIRECT CEREBELLAR TRACT. Is some lectures before the College of Physicians' ${ }^{1}$ I made the observation that in the cervical region in the monkey the posterior roots, on entering the cord, gave a large number of fibres to the direct cerebellar tract. This statement was based on the examination of three cords from monkeys, on which Mr. Horsley had cut the posterior roots of several cervical nerve pairs. In one of these, figured in the abovo lectures, the direct cerebellar tract was largely degenerated, the degeneration being traceable quite distinctly into the restiform body. In the other two, which, at the time of puplishing the lectures, I had not had time to examine carefully, there was also degeneration of the direct cerebellar tract, but on more careful examination there was found in addition some slight descending lesions which could not possibly have been secondary to nerve root section. This circumstance aroused suspicions as to the cause of the degeneration in the first case, and led me to do two more posterior root sections. In one of these, again, there appeared to be a very few degenerated fibres in the direct cerebellar tract, but in no way so extensive as in the three preceding cases. In the other this tract was quite normal. In all these experiments the postero-lateral column and the fibres passing into the horn are strikingly degenerated and broken up. One is forced. then, to the conclusion that in the cases in which the direct cerebellar tract is affected there must have been some lesion of the tract itself. Such a lesion may be inflammatory, or, as Mr. Horsley suggested, a cutting off of the blood supply of the tract by thrombus, or possibly due to a local irritation after a too free use of carbolic acid. I am bound to say, however, in my sections no evidence of any of these influencess can be discovered. In order to eliminate some of these sources of error, I lately made an experimental section of three of the combined anterior and posterior roots on the proximal side of the canglion, without laying open the dura of the cord. In this case the cord shows characteristic secondary degeneration of the postero-lateral column and also of the fan-shaped fibres entering the horn, but the direct cerebellar tract remains intact. I am therefore inclined 10 think that my former statement that the posterior roots enter into the composition of the direct cerebellar tract is erroneous, being based on what I now consider to be an error of experiment.

Harley Street, W.

H. H. Tоотн, M.I.

ROSEOLA BALSAMICA AND ROSEOLA SYPIIILITICA. J. R., aged 21, came under observation on December 16th, 1890 , with a profuse, raised, mostly papular, and very irritable eruption on the trunk, forearms, especially about the back of the wrists and elbows, and front of both thighs. The rash was of a deep red colour, and there were a few abortive wheals on the back. The patient said he had been suffering from gonorrhcea for five or six weeks and had been treating himself with copaiba until the day before, when the rash appeared, the wrists being the parts first affected.

Thus all the usual characters of a rash due to copaiba were present. But it was also noticed that the glands in both groins were enlarged and multiple. On further inquiry the patient stated that a small sore had appeared on the internal surface of the prepuce about the same time as the discharge, and had readily healed under some local application. Neither' sore nor scar could now be seen, either at the spot indicated or elsewhere. The history did not assist the diagnosis, as there had been repeated exposure to the risk of contagion for some time. A saline purgative was ordered.

Three days later the itching had disappeared and the rash also, except that on the abdomen it was still faintly marked. But among these darker red remains of the drug rash there were scattered a few lighter red blotches about the size of a sixpence, and these latter were not at all raised above the

\footnotetext{
1 British Medical Jovenal, april, 1889
} 